\title{
Vigilância das doenças e agravos não transmissíveis - uma iniciativa de mudança no processo de ensino- aprendizagem direcionada a estudantes de graduação em medicina
}

\author{
Daniele Francine Pereira, Lucas Saraiva da Silva, Amanda Vanessa Demarchi, Sandra Costa \\ Fonseca, Regina Fernandes Flauzino, Maria Isabel do Nascimento
}

\begin{abstract}
Resumo
A vigilância das doenças crônicas e agravos não transmissíveis (DANT), um dos eixos do Plano de Ações Estratégicas Para o Enfrentamento das Doenças Crônicas Não Transmissíveis, no Brasil, 2011-2022, concebido pelo Ministério da Saúde, tem sido muito discutida, tornando importante sua inserção em disciplinas de graduação para a formação de profissionais mais preparados a atuarem no atual cenário da saúde. Trata-se de uma ação abrangente, com metas estabelecidas e tem o intuito de conter a epidemia dessas doenças no país. Além disso, cabe destacar seu papel em outros setores da sociedade, como na Educação. O objetivo deste estudo é descrever o modelo de ensinoaprendizagem adotado na disciplina Epidemiologia IV, oferecida à estudantes do oitavo período do curso de medicina, em um Instituto de Saúde Coletiva de uma instituição federal. A disciplina Epidemiologia IV é ministrada com a participação de monitores. É estruturada em dois módulos, um dedicado às doenças transmissíveis e o outro à doenças e agravos não transmissíveis (Módulo de DANT). O foco do Módulo de DANT é principalmente a divulgação do Plano de Enfrentamento e a formação de médicos mais conscientes e ativos no que concerne a produção de informação e ao desenvolvimento de atividades de promoção e prevenção das DANTs. O conteúdo é trabalhado em cinco aulas que contemplam: (i) Vigilância das doenças crônicas não transmissíveis no Brasil apresentação do Plano de Enfrentamento, (ii) Vigilância dos fatores de risco de doenças crônicas no Brasil - com enfoque na obesidade e inatividade física, (iii) Vigilância do tabagismo - com enfoque no método cognitivo comportamental para cessação do tabagismo, (iv) Rastreamento e vigilância do câncer - com enfoque no câncer do colo do útero e no câncer de mama, (v) Vigilância das causas externas - com enfoque na redução do consumo abusivo de álcool, nas quedas e acidentes. A exposição do conteúdo teórico pelo docente e monitores evolui concorrentemente à elaboração de exercícios denominados de norteadores, elaborados pelos alunos no decorrer da aula, de forma interativa. A aula termina com a elaboração de exercícios denominados de finalizadores. Estes são baseados em casos clínicos que reproduzem cenários reais e contemplam o conteúdo da aula, aos quais são atribuídos valores. São feitos em pequenos grupos de alunos e são corrigidos pelo monitor e docente responsável. A estruturação das aulas baseadas em exercícios norteadores tem incrementado a interação discente-docente-monitor e criado um cenário facilitador à divulgação do Plano de Enfrentamento. Embora tenha a limitação de estar em fase incipiente, a expectativa é que a dinâmica da aula também favoreça à formação de profissionais potencialmente envolvidos com o controle das DANTs no Brasil.
\end{abstract}

Descritores: Doença crônica; Educação; Vigilância 